Research Article Animal Genetics

\title{
Meiotic self-pairing of the Psalidodon (Characiformes, Characidae) iso-B chromosome: A successful perpetuation mechanism
}

\author{
Duílio Mazzoni Zerbinato de Andrade Silva ${ }^{1}$ (D), Cristian Araya-Jaime ${ }^{2,3}$, \\ Masakane Yamashita ${ }^{4}$, Mateus Rossetto Vidal ${ }^{1}$, Claudio Oliveira ${ }^{1}$ (D), Fábio Porto-Foresti ${ }^{5}$, \\ Roberto Ferreira Artoni6, ${ }^{6}$ (D) and Fausto Foresti ${ }^{1}$ \\ ${ }^{1}$ Universidade Estadual Paulista (UNESP), Instituto de Biociências de Botucatu, Departamento de Biologia \\ Estrutural e Funcional, Botucatu, SP, Brazil. \\ ${ }^{2}$ Universidad de La Serena, Instituto de Investigación Multidisciplinar en Ciencia y Tecnología, La Serena, \\ Chile. \\ ${ }^{3}$ Universidad de La Serena, Departamento de Biología, Laboratorio de Genética y Citogenética Vegetal, \\ La Serena, Chile. \\ ${ }^{4}$ Hokkaido University, Faculty of Science, Department of Biological Sciences, Laboratory of Reproductive \\ \& Developmental Biology, Sapporo, Japan. \\ ${ }^{5}$ Universidade Estadual Paulista (UNESP), Faculdade de Ciências, Departamento de Ciências Biológicas, \\ Bauru, SP, Brazil. \\ ${ }^{6}$ Universidade Federal de São Carlos (UFSCAR), Departamento de Genética e Evolução, São Carlos, \\ SP, Brazil. \\ ${ }^{7}$ Universidade Estadual de Ponta Grossa (UEPG), Departamento de Biologia Estrutural, Molecular \\ e Genética, Ponta Grossa, PR, Brazil.
}

\begin{abstract}
B chromosomes are non-essential additional genomic elements present in several animal and plant species. In fishes, species of the genus Psalidodon (Characiformes, Characidae) harbor great karyotype diversity, and multiple populations carry different types of non-essential B chromosomes. This study analyzed how the dispensable supernumerary B chromosome of Psalidodon paranae behaves during meiosis to overcome checkpoints and express its own meiosis-specific genes. We visualized the synaptonemal complexes of $P$. paranae individuals with zero, one, or two B chromosomes using immunodetection with anti-medaka SYCP3 antibody and fluorescence in situ hybridization with a $(\mathrm{CA})_{15}$ microsatellite probe. Our results showed that $B$ chromosomes self-pair in cells containing only one B chromosome. In cells with two identical B chromosomes, these elements remain as separate synaptonemal complexes or close self-paired elements in the nucleus territory. Overall, we reveal that B chromosomes can escape meiotic silencing of unsynapsed chromatin through a self-pairing process, allowing expression of their own genes to facilitate regular meiosis resulting in fertile individuals. This behavior, also seen in other congeneric species, might be related to their maintenance throughout the evolutionary history of Psalidodon.
\end{abstract}

Keywords: Tetra fish, synaptonemal complex, SYCP3, meiotic silencing of unsynapsed chromatin (MSUC), fish meiosis.

Received: March 20, 2021; Accepted: August 14, 2021.

\section{Introduction}

Meiosis is a highly regulated process of reduced cell division occurring in germ cells, which allows for genetic recombination (Ma et al., 2014). During prophase $\mathrm{I}$, homologous chromosomes are recognized and paired via synaptonemal complexes (SC), a protein structure formed between chromosomes. This structure is thought to mediate chromosome pairing, synapse, and even recombination. Meiotic silencing of unsynapsed chromatin (MSUC) significantly reduces transcriptional activity until the chromosomes reach

Send correspondence to Duílio Mazzoni Zerbinato de Andrade Silva. Universidade Estadual Paulista, Instituto de Biociências de Botucatu, Departamento de Biologia Estrutural e Funcional, Rua Prof. Dr. Antônio Celso Wagner Zanin, 250, Distrito de Rubião Junior, Botucatu, SP, 18618-970, Brazil. Email: duilio.silva@unesp.br. their maximum state of pairing in the pachytene phase (Turner, 2015). MSUC seems to be involved in controlling nonhomologous recombination (McKee and Handel, 1993; Zhang et al., 2014) and activating the processes of cell death in cases of synapse failure (Faisal and Kauppi, 2016).

$\mathrm{B}$ chromosomes are non-essential additional genomic elements that (in most cases) arise from autosomal chromosomes and follow their own evolutionary path through various types of genome rearrangements, losing the ability to properly pair and recombine with A chromosomes (Houben et al., 2014). To perpetuate in the species, B chromosomes need to pair properly, avoiding meiosis disruption in a destructive manner. Cases where B chromosomes pair with each other to form bivalents, trivalents, and multivalents have been reported in literature (e.g. Pauls and Bertollo, 1983; Dias et al., 1998; Basheva et al., 2010; Serrano et al., 2016). This element frequently 
forms a univalent in cells with only one B chromosome, resulting in irregular meiosis. (Battaglia, 1964; Pauls and Bertollo, 1983; Shi et al., 1988; Dias et al., 1998; Basheva et al., 2010; Aquino et al., 2013; Pires et al., 2015; Serrano et al., 2016). Interestingly, iso-B chromosomes, reported in several species (Fletcher and Hewitt, 1988; Dias et al., 1998; Mestriner et al., 2000; Poletto et al., 2010; Valente et al., 2014; Pires et al., 2015), have the advantage of being composed of highly similar arms, allowing their perfect selfpairing, thus decreasing possible damage to cell division and increasing their chances of perpetuation (Battaglia, 1964; Mestriner et al., 2000; Serrano-Freitas et al., 2020).

The recently resurrected and expanded genus Psalidodon (Characiformes, Characidae) (Terán et al., 2020) includes species that formally belonged to the Astyanax genus, including P. paranae and P. scabripinnis, among others. These species harbor great karyotype diversity (Pazza et al., 2018) with several populations carrying different types of B chromosomes (Review in Silva et al., 2021). Among these species, the large metacentric B chromosome of P. scabripinnis was described as an isochromosome based on its self-pairing in meiotic cells and the symmetry of its arms as revealed by As51 satellite DNA mapping (Mestriner et al., 2000). This chromosome shares a common origin with the $\mathrm{B}$ chromosome of $P$. paranae (Silva et al., 2021), which is also an isochromosome based on the mapping of several repetitive DNAs (Silva et al., 2014, 2016, 2017). However, meiotic analyses have not yet been performed on this chromosome.

In this study, we analyzed the meiotic behavior of the $\mathrm{B}$ chromosome of $P$. paranae in individuals with one or two B chromosomes through synaptonemal complex immunodetection using an anti-medaka SYCP3 antibody and fluorescence in situ hybridization (FISH) using a (CA) microsatellite probe. We used an adaptation of the technique described by Araya-Jaime et al. (2015) to unveil the pairing mechanism employed by these elements to overcome the meiosis checkpoints and achieve evolutionary success in Psalidodon. We also examined the upregulation of a meiosisspecific gene present on the B chromosome (mutS homolog 4 - msh4) in the gonads of B-carrying individuals, to determine the pairing behavior of these extra elements.

\section{Material and Methods}

\section{Sampling and measurement of B chromosome number}

Ten females, seven males and one intersex individual of $P$. paranae from the population of Cascatinha stream, Botucatu, São Paulo, Brazil (22 53' 22.5' S, 48²9' 22.4" W) were analyzed. The intersex individual was identified by the presence of oocytes and spermatozoa under a microscopy analysis of the gonads. Previous studies reported the presence of B chromosomes in some individuals of this population (Maistro et al., 1994b; Porto-Foresti et al., 1997). The animals were collected in accordance with Brazilian environmental protection legislation (Collection Permission MMA/IBAMA/ SISBIO-number 3245) and the procedures for fish sampling, maintenance, and analysis were performed in compliance with the Brazilian College of Animal Experimentation (COBEA) and approved (protocol 504) by the BIOSCIENCE INSTITUTE/UNESP ETHICS COMMITTEE ON THE USE OF ANIMALS (CEUA). The specimens were identified and deposited at the fish collection of the Laboratório de Biologia e Genética de Peixes, Botucatu, São Paulo, Brazil, under the voucher LBP19572 (P. paranae). The animals were anesthetized and dissected, and then mitotic chromosome preparations were obtained following the protocol described by Foresti et al. (1981). C-banding was performed according to the protocol described by Sumner (1972) to improve accuracy in measuring the number of B chromosomes in the samples. Chromosome preparations were stained for 5 minutes with $5 \%$ Giemsa solution in phosphate buffer $(\mathrm{pH}=6.7)$.

\section{Synaptonemal complex analysis and fluorescence in situ hybridization}

Synaptonemal complex preparations were performed according to Araya-Jaime et al. (2015) using immature males and females. The SCs were stained using silver nitrate and immunodetected using an anti-medaka SYCP3 primary antibody/FITC-labeled secondary antibody. Subsequent FISH technique on mitotic preparations and meiotic spreads (SCFISH) was conducted according to the protocol described by Cioffi et al. (2011) using the (CA) $)_{15}$ oligonucleotide as probe. This probe was directly labeled with Cy3 during synthesis, as described by Kubat et al. (2008). This microsatellite was selected as a probe due to its high accumulation in the terminal region of both $\mathrm{B}$ chromosome arms at high visible sites (Silva et al., 2016) (Figure 1). Chromosomes were counterstained with 4',6-Diamidino-2-phenylindole (DAPI) (Vector Laboratories, Burlingame, CA). Images were captured with a digital camera (Olympus DP90) attached to an Olympus BX61 epifluorescence photomicroscope and acquired using CellSens Dimension (Olympus). Image treatment, optimization of brightness and contrast were performed using the Adobe Photoshop CS4 program. Meiotic phases were identified according to Toscani et al. (2008), Ribagorda et al. (2019) and Spangenberg et al. (2019).

\section{Quantitative reverse transcription PCR (RT-qPCR)}

Quantification of expression levels of $m s h 4$ gene was performed using gonads from females and males with and without $\mathrm{B}$ chromosomes. We analyzed four ovaries $0 \mathrm{~B}$, six ovaries $1 \mathrm{~B}$, four testes $\mathrm{OB}$ and three testes $1 \mathrm{~B}$. After dissection, tissues were immediately frozen in liquid nitrogen and stored at $-70^{\circ} \mathrm{C}$. RNA was extracted using the TRIzol ${ }^{\circledR}$ Kit (Invitrogen), following the manufacturer's instructions. Subsequently, the samples were treated with DNAseI (Thermo Fisher Scientific) and were checked on 1\% agarose gel and on a 2100 Bioanalyzer ${ }^{\circledR}$ (Agilent) equipment. Only RNA samples with an A260/280 ratio of 1.8-2.0, A260/230 ratio > 2.0 , and RIN $>7$ were used for subsequent analysis. The cDNA for each sample was synthesized using the High-Capacity cDNA Reverse Transcription Kit ${ }^{\circledR}$ (Thermo Fisher Scientific, USA) using $1 \mu \mathrm{g}$ per sample of total RNA, following the manufacturer's instructions. The cDNA obtained was diluted in RNase-DNase free water for a 1:50 working solution. 


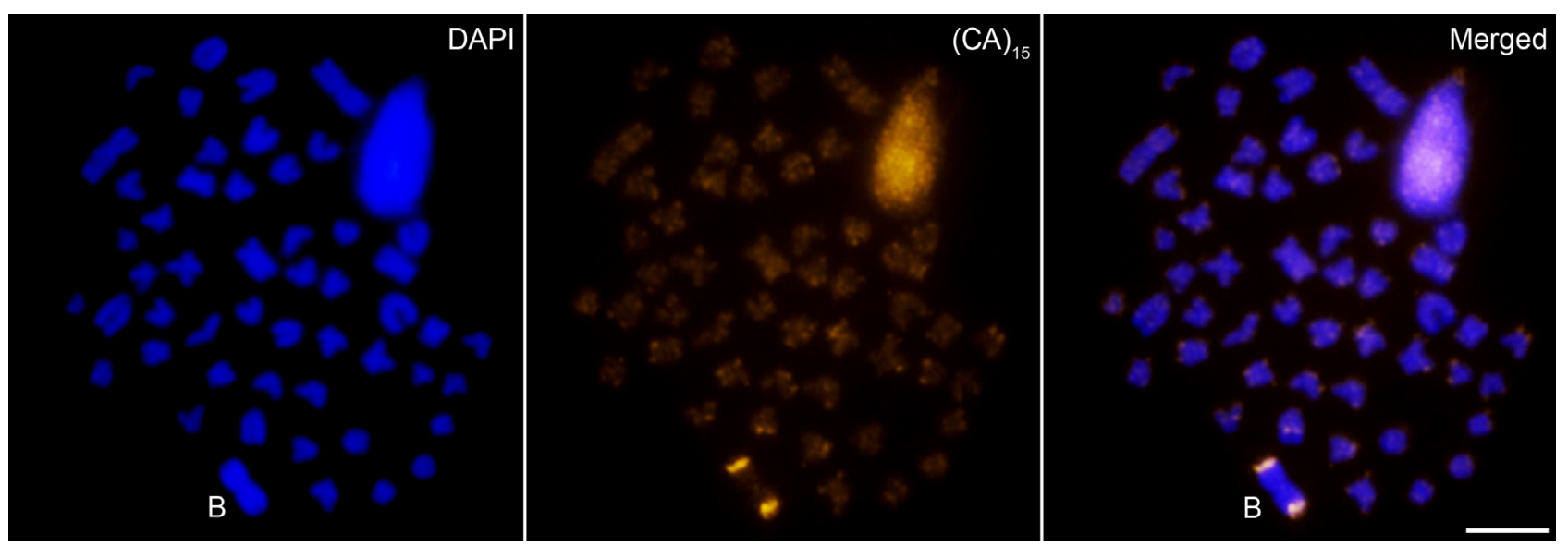

Figure 1 - Metaphase of $P$. paranae $(2 \mathrm{n}=50+\mathrm{B})$ after FISH with a $(\mathrm{CA})_{15}$ probe. Chromosomes were counterstained with DAPI. Bar $=10 \mu \mathrm{m}$.

For RT-qPCR reactions, we used the primers for $m s h 4$ gene designed by Silva et al. (2021). Quantitative PCR was performed on QuantStudio ${ }^{\mathrm{TM}} 12 \mathrm{~K}$ Flex Real-Time PCR Systems (Thermo Fisher Scientific, USA). The reactions were performed in a final volume of $10 \mu \mathrm{L}$, with $1 \mu \mathrm{l}$ of cDNA, 5 $\mu$ of Power SYBR ${ }^{\mathrm{TM}}$ Green PCR Master Mix (Thermo Fisher Scientific) and $1 \mu 1$ of each $5 \mu \mathrm{M}$ primer. Cycle conditions were $95^{\circ} \mathrm{C}$ for $10 \mathrm{~min} ; 45$ cycles of $95^{\circ} \mathrm{C}$ for $15 \mathrm{~s}$, and $60^{\circ} \mathrm{C}$ for 1 min. Target and reference genes were analyzed simultaneously in duplicates for two independent samples. The normalized relative expression quantity (NREQ) was determined by the $2^{-\Delta \Delta \mathrm{Cq}}$ method (Livak and Schmittgen, 2001). The $m s h 4$ expression levels were normalized using the hypoxanthine phosphoribosyltransferase 1 (hprtl) as the reference gene, with subsequent calibration to the average expression of the OB group. The specificity of the PCR products was confirmed by dissociation curve analysis.

Two-group comparisons were performed by the GardnerAltman estimation plot method devised by Ho et al. (2019) following Gardner and Altman's design (1986), as implemented on https://www.estimationstats.com/.

\section{Results}

Meiocytes from five females (one $0 \mathrm{~B}$, three $1 \mathrm{~B}$ and one not determined), five males (three $0 \mathrm{~B}$, one $1 \mathrm{~B}$ and one $2 \mathrm{~B}$ ), and one intersex individual (0B) were analyzed. Overall, 48 meiocytes were analyzed, with an average of 4.8 cells analyzed per individual.

Silver nitrate staining of SCs revealed 25 bivalents in $0 \mathrm{~B}$ individuals during the pachytene phase (Figure 2A), whereas in $1 \mathrm{~B}$ individuals 26 completely paired SCs were observed (Figure 2B). The meiocytes of 2B individuals showed 26 $\mathrm{SCs}$ (Figure 2C). No differences between males and females were observed.

Immunodetection analysis of SC revealed 25 bivalents in the $0 \mathrm{~B}$ individuals (Figure $\mathrm{S} 1$ ). The SC-FISH assay revealed 25 fully synaptized bivalents in $1 \mathrm{~B}$ individuals. As the B chromosome has conspicuous $(\mathrm{CA})_{15}$ sites in both terminal regions (Figure 1), the assay also showed a SC marked by the $(\mathrm{CA})_{15}$ probe in only one of the ends, corresponding to the self-paired B chromosome (Figure 3A-C). In addition to 25 fully synaptized SCs, SC-FISH in 2B individual preparations showed a SC association marked on only one end by the (CA) ${ }_{15}$ probe, corresponding to two self-paired and close B chromosomes (Figure 3E-G). A region not fully associated with the two SCs was observed in this structure (Figure 3E). In some pachytene preparations of $2 \mathrm{~B}$ individuals, 25 normal bivalents plus two SCs marked by the $(\mathrm{CA})_{15}$ probe were seen at only one of the ends, corresponding to two independently self-paired B chromosomes (Figure 3I-K).

The meiotic behavior of two self-paired B chromosomes can be observed in Figure 4. In early diplotene, the formation of a "ring-like" figure can be observed with the chromosomes united at their ends (Figure 4A-C). In more advanced stages of diplotene, complete dissociation of the $\mathrm{B}$ chromosomes shown as univalent was observed, apparently in a state of dissociation more advanced in relation to the chromosomes of the A complement (Figure 4D). The pairing patterns of $P$. paranae $\mathrm{B}$ chromosomes are illustrated in Figure $3 \mathrm{D}, \mathrm{H}, \mathrm{L}$.

No variation was observed in the number of $B$ chromosomes among the meiotic cells of each specimen. Thus, the $0 \mathrm{~B}, 1 \mathrm{~B}$, and $2 \mathrm{~B}$ individuals presented zero, one, and two B chromosomes in all their meiotic cells, respectively. No regions with failure in synapsis were observed among the chromosomes of the A complement in individuals of both sexes of $P$. paranae (Figures 2 and 3), suggesting the absence of proto-sex chromosomes at differentiation status (Murata et al., 2016). To the best of our knowledge, no sexrelated chromosomal polymorphism has been described in the genus Psalidodon.

Transcription levels for the $m s h 4$ gene were about the 12-fold effect size (mean differences) in 1B ovaries compared to those in $0 \mathrm{~B}$ ones. In the testes, this difference was about 4-fold (Figure 5, Table S1). These results demonstrate upregulation of the msh 4 gene in the ovaries and testes of B-carrying individuals. 


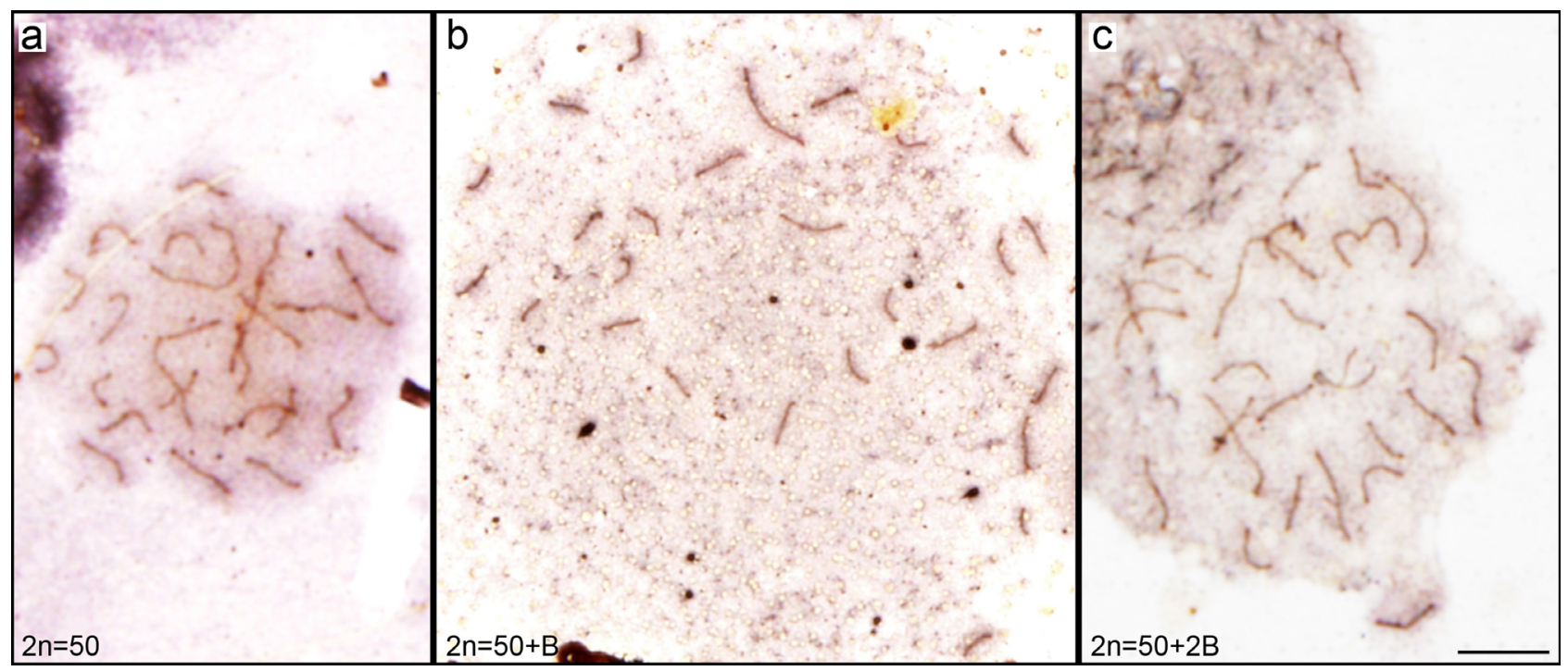

Figure 2 - Detection of $P$. paranae synaptonemal complexes by silver nitrate staining (A, B, C). Diploid numbers of individuals are indicated in the lower left corner. Bar $=10 \mu \mathrm{m}$.

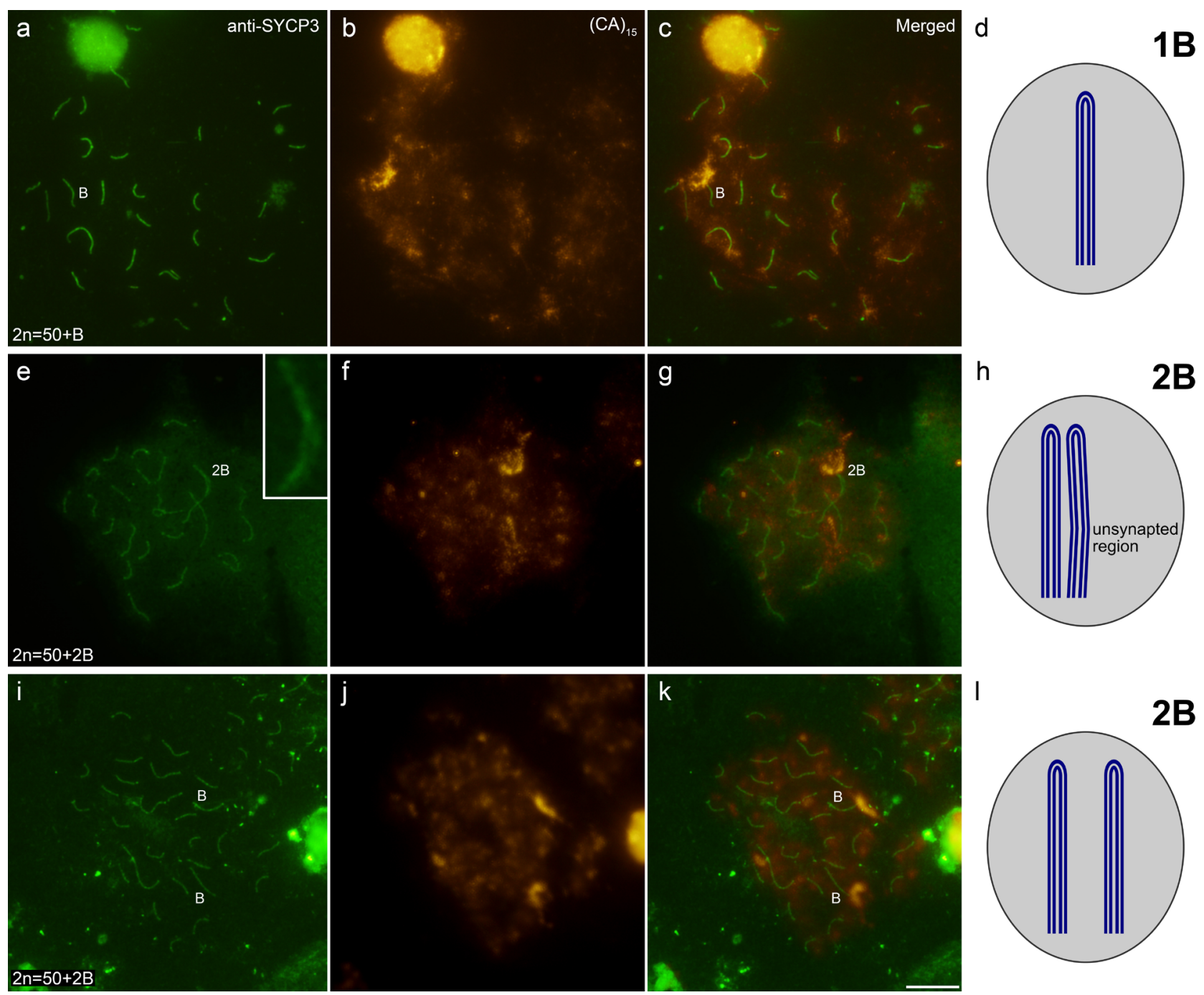

Figure 3 - Detection of $P$. paranae synaptonemal complexes through immunodetection using an anti-medaka SYCP3 antibody (A, E, I) and FISH with a $(\mathrm{CA})_{15}$ probe (B, F, J). Diploid number of individuals are indicated in the lower left corner (A, E, I). In the inset of e, note a region not fully associated in the lower half of the SC association formed by two self-paired B chromosomes. C, G, and K show the combination of images obtained by immunodetection and FISH. D, H, and L present an illustration of the meiotic behavior of the B chromosome. In all individuals, B chromosomes show a self-pairing behavior and in 2B individuals, they can stay close or separated. In the first case, they can appear not perfectly paired to each other. Bar $=10 \mu \mathrm{m}$. 

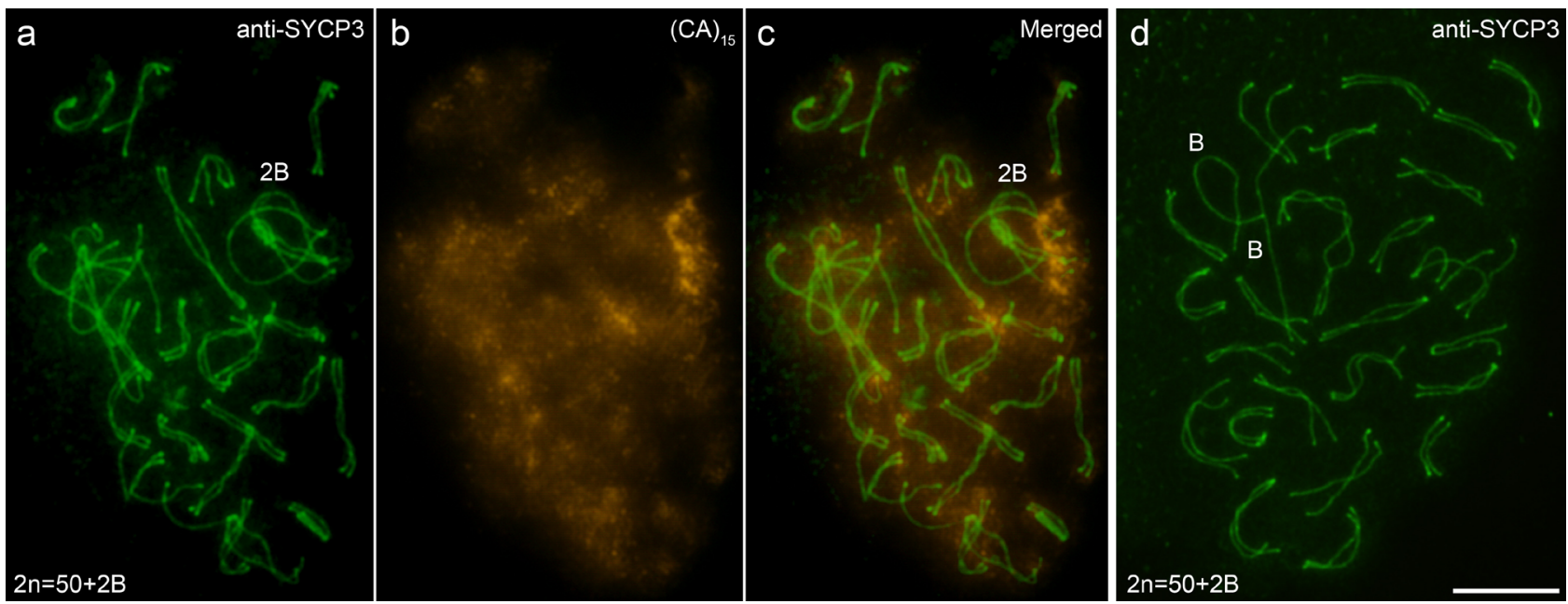

Figure 4 - Diplotene images of $P$. paranae after immunodetection using anti-medaka SYCP3 antibody and SC-FISH assay using the (CA) ${ }_{15}$ probe (A, $\mathrm{B}, \mathrm{C})$ and the late-diplotene stages after immunodetection using the anti-medaka SYCP3 antibody (D). Diploid numbers of individuals are indicated in the lower left corners of images a and $\mathrm{d}$. Note that in $\mathrm{d}$, the B chromosomes are entirely dissociated, and are shown as univalents. Bar $=10 \mu \mathrm{m}$.
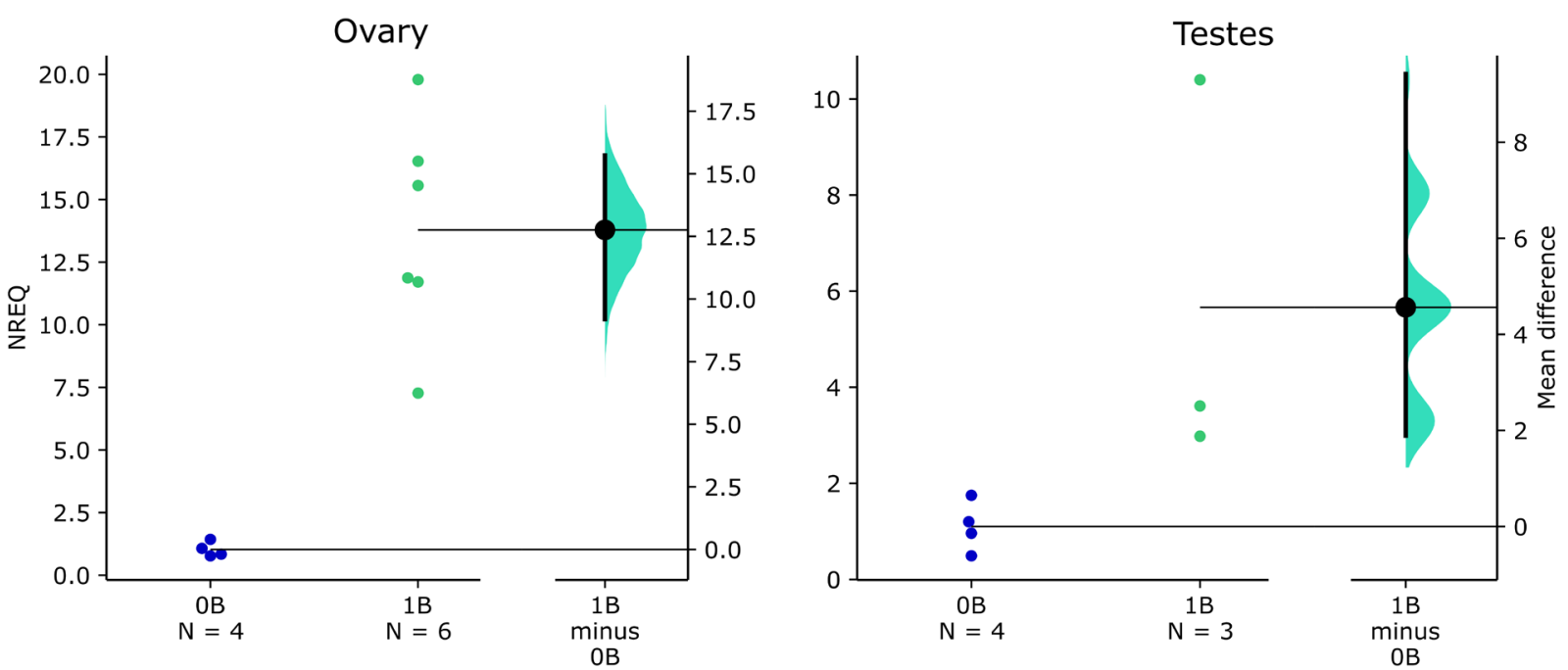

Figure 5 - Gardner-Altman estimation plots showing $m s h 4$ transcription levels in 0B and 1B individuals, as analyzed by RT-qPCR. Both groups are plotted on the left axes, and the mean difference (effect size) is plotted on a floating axe at the right as a bootstrap sampling distribution. The mean difference is depicted as a black dot, and the $95 \%$ confidence interval is indicated by the ends of the vertical error bar. NREQ = normalized relative expression quantity.

\section{Discussion}

Meiotic self-pairing of iso-B chromosomes can allow them to advance through meiosis checkpoints and may be responsible for the success of their perpetuation (review in Clark et al., 2017; Silva et al., 2021). This behavior could allow B chromosomes without homologous pairs to circumvent the MSUC process. Thus, a selection pressure favoring the B isochromosomes would exist, as the MSUC process might lead to cell death in cases of synapse failure (Faisal and Kauppi, 2016). Our results thus demonstrate that B chromosomes of P. paranae, previously described as isochromosomes (Silva et al., 2014), can self-pair as observed in the B chromosome of its sister species, P. scabripinnis (Mestriner et al., 2000). After diverging for millions of years (Silva et al., 2021), both chromosomes still have self-pairing capacity, reinforcing the role of this behavior as one of the main mechanisms responsible for maintaining such chromosomes in the populations of Psalidodon
The success of B chromosomes is mainly related to their accumulation in populations due to transmission rates higher than 0.5 , as expected by Mendelian laws. This process is called drive and occurs due to the patterns of B chromosome segregation (Camacho et al., 2005). As the techniques used here did not enable us to observe all the meiotic phases, we cannot verify whether the patterns of B chromosome segregation are influenced by other factors (Wu et al., 2019). The increased frequency of B chromosomes in the analyzed population (Goes, in prep.) might be related to their ability to circumvent the MSUC process and remain undetected or cause deleterious effects in carriers.

B chromosomes are mainly composed of repetitive DNA sequences related to chromosome folding, recombination, meiotic pairing, and even disjunction in the germ line tissue (review in Garrido-Ramos, 2017); further, in several cases, pairing between $\mathrm{B}$ chromosomes was attributed to their homologous content (Pauls and Bertollo, 1983; Switonski 
et al., 1987; Kolomiets et al., 1988; Maistro et al., 1994a; De Brito Portela-Castro et al., 2001; Serrano et al., 2016). In this manner, repetitive DNA sequences symmetrically distributed on B chromosomes of $P$. paranae and P. scabripinnis (Mestriner et al., 2000; Silva et al., 2014, 2016, 2017; Artoni et al., 2015) would then be responsible for self-pairing and symmetry maintenance could be essential for perpetuating this advantageous behavior.

In individuals with two B chromosomes, these elements are self-paired, even though the association between them is facultative (Figure $3 \mathrm{G}, \mathrm{K}$ ). As discussed, self-pairing of $\mathrm{B}$ chromosomes may represent an adaptive advantage. Association of two self-paired B chromosomes might not be required to circumvent the MSUC process, because selfpaired B chromosomes do not have unsynapsed regions. The association between two B chromosomes observed here appears to result from their homologous content recognition and/or their physical proximity to specific territories inside the nucleus (Schemczssen-Graeff et al., 2020). When B chromosomes are associated, we observe synaptic regions forming between chromatids (Figure 4A), as the employed technique preserves chromosomal associations and avoids the "squash" procedure (Araya-Jaime et al., 2015).

Self-pairing of B chromosomes can favor homogenization of their sequences through regular recombination (Rice, 1994; Basheva et al., 2010). The low diversification of ITS1 and ITS2 regions on the $\mathrm{B}$ chromosome of $P$. paranae was attributed to this phenomenon by Silva et al. (2014). Regular recombination can also be responsible for the conservation of protein-coding sequences observed on the $\mathrm{B}$ chromosomes of $P$. paranae and P. scabripinnis (Silva et al., 2021). This conservation was indicated by the presence of a few B-specific SNPs and complete coding regions on these chromosomes (Silva et al., 2021). Similarly, natural selection has preserved the sequences of apparently intact and functional c-KIT on the B chromosome of foxes (Graphodatsky et al., 2005; Yudkin et al., 2007). In this case, recombination of $\mathrm{B}$ chromosomes was considered a protective mechanism for copies of this gene against mutational meltdown and degeneration (Basheva et al., 2010).

Unpaired B chromosomes can be silenced at meiosis (Serrano et al., 2016), as observed in unpaired regions in the fungus Neurospora crassa (Sordariales, Sordariaceae) (Shiu and Metzenberg, 2002) and in mice (Turner et al., 2005). Self-pairing of B chromosomes, observed in P. paranae (this study) and in P. scabripinnis by Mestriner et al. (2000), could allow them to escape from silencing epigenetic modifications of the MSUC process, resulting in the transcriptional activity of these chromosomes (Serrano et al., 2016). Accordingly, Silva et al. (2021) identified the expression of B-specific transcripts of important genes related to the cell cycle and gonadal development in the ovaries of both species, revealing that the B chromosomes are not silenced during meiosis.

Among them, the $m s h 4$ gene, a meiosis-specific homologue of the bacterial MutS protein, is essential for meiotic recombination and proper segregation of homologous chromosomes. In mice, meiosis is severely disrupted in MSH4 mutant males and females, resulting in infertility (Kneitz et al., 2000; Dai et al., 2017). We consider that transcription of the $m s h 4$ gene on the B chromosomes of P. paranae and
P. scabripinnis helps ensure the required conditions for the proper division of cells carrying extra elements with atypical pairing. We observed upregulation of this gene in the ovaries and testes of $1 \mathrm{~B}$ individuals of $P$. paranae, highlighting their role during the divisions leading to gonad formation in both sexes.

In conclusion, this study shows that the B chromosomes of $P$. paranae and $P$. scabripinnis can express their own meiosis-specific genes by escaping the MSUC through meiotic self-pairing. This ancient behavior results in regular meiosis and fertile individuals, allowing the evolutionary success and maintenance of B chromosomes throughout the evolutionary history of Psalidodon. Extension of these analyses beyond the iso-B chromosomes of Psalidodon is necessary to comprehend how non-isochromosome behavior perpetuates in this genus. The use of controlled crosses could provide information about the segregation patterns and transmission rates of the B chromosome in P. paranae.

\section{Acknowledgements}

This study was supported by grants from Fundação de Amparo à Pesquisa do Estado de São Paulo (FAPESP) (grants 2014/09634-5, 2017/15608-5 to FF; 2013/24143-5, 2017/22447-8 to DMZAS and 2018/20610-1, 2016/09204-6, 2014/26508-3 to CO), Coordenação de Aperfeiçoamento de Pessoal de Nível Superior (CAPES), Conselho Nacional de Desenvolvimento Científico e Tecnológico (CNPq) (grant 306054/2006-0 to CO), Doctorado en el Exterior, Becas-Chile (grant 72110694 to CAJ). We are thankful to Maria Soledad Berrios for providing helpful suggestions.

\section{Conflict of Interest}

All authors have no conflicts of interest to declare.

\section{Author Contributions}

Conceptualization: DMZAS, CAJ, MY, CO, FPF, RFA, FF; experimental design: DMZAS, CAJ, MY, CO, FPF, RFA, FF; collected samples: DMZAS, CAJ, MRV; cytogenetics analyses: DMZAS, CAJ, MY, MRV, CO, FPF, RFA, FF; contributed with reagents/materials/analysis tools: DMZAS, CAJ, MY, CO, FPF, RFA, FF. All authors wrote, read, and approved the manuscript.

\section{References}

Aquino CI, Abril VV and Duarte JMB (2013) Meiotic pairing of B chromosomes, multiple sexual system, and Robertsonian fusion in the red brocket deer Mazama americana (Mammalia, Cervidae). Genet Mol Res 12:3566-3574.

Araya-Jaime C, Serrano ÉA, Silva DMZA, Yamashita M, Iwai T, Oliveira $C$ and Foresti F (2015) Surface-spreading technique of meiotic cells and immunodetection of synaptonemal complex proteins in teleostean fishes. Mol Cytogenet 8:4-9.

Artoni RF, Castro JP, Jacobina UP, Lima-Filho PA, Costa GWWF and Molina WF (2015) Inferring diversity and evolution in fish by means of integrative molecular cytogenetics. Sci World J 2015:365787

Basheva EA, Torgasheva AA, Sakaeva GR, Bidau C and Borodin PM (2010) A- and B-chromosome pairing and recombination in male meiosis of the silver fox (Vulpes vulpes L., 1758, Carnivora, Canidae). Chromosome Res 18:689-696. 
Battaglia E (1964) Cytogenetics of B-Chromosomes. Caryologia 17:245-299.

Camacho JPM (2005) B Chromosomes. In: Gregory TR (ed). The evolution of the genome. Elsevier, San Diego, pp. 223-286.

Cioffi MB, Kejnovsky E and Bertollo LAC (2011) The chromosomal distribution of microsatellite repeats in the genome of the wolf fish Hoplias malabaricus, focusing on the sex chromosomes. Cytogenet Genome Res 132:289-296.

Clark FE, Conte MA, Ferreira-Bravo IA, Poletto AB, Martins C and Kocher TD (2017) Dynamic sequence evolution of a sex-Associated b chromosome in lake Malawi cichlid fish. J Hered 108:53-62.

Dai J, Voloshin O, Potapova S and Camerini-Otero RD (2017) Meiotic knockdown and complementation reveals essential role of RAD51 in mouse spermatogenesis. Cell Rep 18:1383-1394.

Dias AL, Foresti F and Oliveira C (1998) Synapsis in supernumerary chromosomes of Prochilodus lineatus (Teleostei: Prochilodontidae). Caryologia 51:105-113.

Faisal I and Kauppi L (2016) Sex chromosome recombination failure, apoptosis, and fertility in male mice. Chromosoma 125:227-235.

Fletcher HL and Hewitt GM (1988) Synaptonemal complexes of univalent B chromosomes in the grasshoppers Euthystira brachyptera and Myrmeleotettix maculatus. Heredity 60 : 383-386.

Foresti F, Almeida-Toledo LF and Toledo-Filho SA (1981) Polymorphic nature of nucleolus organizer regions in fishes. Cytogenet. Cell Genet 31:137-144.

Gardner MJ and Altman DG (1986) Confidence intervals rather than P values: Estimation rather than hypothesis testing. $\mathrm{Br}$ Med J 292:746-750.

Garrido-Ramos MA(2017) Satellite DNA: An evolving topic. Genes (Basel) 8:230.

Graphodatsky AS, Kukekova AV, Yudkin DV, Trifonov VA, Vorobieva NV, Beklemisheva VR, Perelman PL, Graphodatskaya DA, Trut LN, Yang F et al. (2005) The proto-oncogene C-KIT maps to canid B-chromosomes. Chromosome Res 13:113-122.

Ho J, Tumkaya T, Aryal S, Choi H and Claridge-Chang A (2019) Moving beyond $\mathrm{P}$ values: Data analysis with estimation graphics. Nat Methods 16:565-566.

Houben A, Banaei-Moghaddam AM, Klemme S and Timmis JN (2014) Evolution and biology of supernumerary B chromosomes. Cell Mol Life Sci 71:467-478.

Kneitz B, Cohen PE, Avdievich E, Zhu L, Kane MF, Hou H, Kolodner RD, Kucherlapati R, Pollard JW and Edelmann W (2000) MutS homolog 4 localization to meiotic chromosomes is required for chromosome pairing during meiosis in male and female mice. Genes Dev 14:1085-1097.

Kolomiets OL, Borbiev TE, Safronova LD, Borisov YM and Bogdanov YF (1988) Synaptonemal analysis of B chromosome behaviour in meiotic prophase I in the East-Asiatic mouse Apodemus peninsulae (Muridae, Rodentia). Cytogenet Cell Genet 48:183-187.

Kubat Z, Hobza R, Vyskot B and Kejnovsky E (2008) Microsatellite accumulation on the $\mathrm{Y}$ chromosome in Silene latifolia. Genome $51: 350-356$.

Livak KJ and Schmittgen TD (2001) Analysis of relative gene expression data using real-time quantitative PCR and the $2^{-\triangle \Delta C \mathrm{CT}}$ method. Methods 25:402-408.

Ma H, Cooke HJ and Shi Q (2014) Meiosis: Recent progress and new opportunities. J Genet Genomics 41:83-85.

Maistro EL, Dias AL, Foresti F, Oliveira C and Moreira-Filho O (1994a) Natural triploidy in Astyanax scabripinnis (Pisces, Characidae) and simultaneous occurrence of macro Bchromosomes. Caryologia 47:233-239.
Maistro EL, Foresti F and Oliveira C (1994b) New occurrence of a macro B-chromosome in Astyanax scabripinnis paranae (Pisces, Characiformes, Characidae). Rev Bras Genet 17:153-156.

McKee BD and Handel MA(1993) Sex chromosomes, recombination, and chromatin conformation. Chromosoma 102:71-80.

Mestriner CA, Galetti PM, Valentini SR, Ruiz IRG, Abel LDS, Moreira-Filho O and Camacho JPM (2000) Structural and functional evidence that a $\mathrm{B}$ chromosome in the characid fish Astyanax scabripinnis is an isochromosome. Heredity 85:1-9.

Murata C, Sawaya H, Nakata K, Yamada F, Imoto I and Kuroiwa A (2016) The cryptic Y-autosome translocation in the small Indian mongoose, Herpestes auropunctatus, revealed by molecular cytogenetic approaches. Chromosoma 125:807-815.

Pauls E and Bertollo LAC (1983) Evidence for a system of supernumerary chromosomes in Prochilodus scrofa steindachner, 1881 (Pisces, prochilodontidae). Caryologia 36:307-314.

Pazza R, Dergam JA and Kavalco KF (2018) Trends in karyotype evolution in Astyanax (Teleostei, Characiformes, Characidae): Insights from molecular data. Front Genet 9:131.

Pires LB, Sampaio TR and Dias AL (2015) Mitotic and meiotic behavior of B chromosomes in Crenicichla lepidota: New report in the family cichlidae. J Hered 106:289-295.

Poletto AB, Ferreira IA and Martins C (2010) The B chromosomes of the African cichlid fish Haplochromis obliquidens harbour 18S rRNA gene copies. BMC Genet 11:1-8.

Portela-Castro ALB, Julio Júnior HF and Nishiyama PB (2001) New occurrence of microchromosomes B in Moenkhausia sanctaefilomenae (Pisces, Characidae) from the Paraná River of Brazil: Analysis of the synaptonemal complex. Genetica 110:277-283.

Porto-Foresti F, Oliveira C, Maistro EL and Foresti F (1997) Estimated frequency of B-chromosomes and population density of Astyanax scabripinnis paranae in a small stream. Braz $\mathrm{J}$ Genet 20:3

Ribagorda M, Berríos S, Solano E, Ayarza E, Martín-Ruiz M, Gil-Fernández A, Parra MT, Viera A, Rufas JS, Capanna E et al. (2019) Meiotic behavior of a complex hexavalent in heterozygous mice for Robertsonian translocations: Insights for synapsis dynamics. Chromosoma 128:149-163.

Rice WC (1994) Degeneration of a nonrecombining chromosome. Science 263:230-232.

Schemczssen-Graeff Z, Barbosa P, Castro JP, Silva DMZA, Almeida MC, Moreira-Filho O and Artoni RF (2020) Dynamics of replication and nuclear localization of the $\mathrm{B}$ Chromosome in kidney tissue cells in Astyanax scabripinnis (Teleostei: Characidae). Zebrafish 17:147-152.

Serrano EA, Araya-Jaime C, Suárez-Villota EY, Oliveira C and Foresti F (2016) Meiotic behavior and H3K4m distribution in B chromosomes of Characidium gomesi (Characiformes, Crenuchidae). Comp Cytogenet 10:255-268a.

Serrano-Freitas EA, Silva DMZA, Ruiz-Ruano FJ, Utsunomia R, Araya-Jaime C, Oliveira C, Camacho JPM and Foresti F (2020) Satellite DNA content of B chromosomes in the characid fish Characidium gomesi supports their origin from sex chromosomes. Mol Genet Genom 295:195-207.

Shi L, Tang L, Ma K and Ma C (1988) Synaptonemal complex formation among supernumerary B chromosomes: An electron microscopic study on spermatocytes of Chinese raccoon dogs. Chromosoma 97:178-183.

Shiu PKT and Metzenberg RL (2002) Meiotic silencing by unpaired DNA: Properties, regulation and suppression. Genetics 161:1483-1495.

Silva DMZA, Daniel SN, Camacho JPM, Utsunomia R, Ruiz-Ruano FJ, Penitente M, Pansonato-Alves JC, Hashimoto DT, Oliveira $\mathrm{C}$, Porto-Foresti $\mathrm{F}$ et al. (2016) Origin of B chromosomes in 
the genus Astyanax (Characiformes, Characidae) and the limits of chromosome painting. Mol Genet Genom 291:1407-1418.

Silva DMZA, Pansonato-Alves JC, Utsunomia R, Araya-Jaime C, Ruiz-Ruano FJ, Daniel SN, Hashimoto DT, Oliveira C, Camacho JPM, Porto-Foresti F et al. (2014) Delimiting the origin of a B chromosome by FISH mapping, chromosome painting and DNA sequence analysis in Astyanax paranae (Teleostei, Characiformes). PLoS ONE 9:33-36.

Silva DMZA, Ruiz-Ruano FJ, Utsunomia R, Martín-Peciña M, Castro JP, Freire PP, Carvalho RF, Hashimoto DT, Suh A, Oliveira C et al. (2021) Long-term persistence of supernumerary B chromosomes in multiple species of Astyanax fish. BMC Biol 19:52.

Silva DMZA, Utsunomia R, Ruiz-Ruano FJ, Daniel SN, PortoForesti F, Hashimoto DT, Oliveira C, Camacho JPM and Foresti F. (2017) High-throughput analysis unveils a highly shared satellite DNA library among three species of fish genus Astyanax. Sci Rep. 7:1-12.

Spangenberg V, Arakelyan M, Galoyan E, Pankin M, Petrosyan R, Stepanyan I, Grishaeva T, Danielyan F and Kolomiets O (2019) Extraordinary centromeres: Differences in the meiotic chromosomes of two rock lizards species Darevskia portschinskii and Darevskia raddei. PeerJ 7:e6360

Sumner AT (1972) A simple technique for demonstrating centromeric heterochromatin. Exp Cell Res 75:304-306.

Switonski M, Gustavsson I, Höjer K and Plöen L (1987) Synaptonemal complex analysis of the B-chromosomes in spermatocytes of the silver fox (Vulpes vulpes Desm.). Cytogenet Cell Genet 45:84-92.

Terán GE, Benitez MF and Mirande JM (2020) Opening the Trojan horse: Phylogeny of Astyanax, two new genera and resurrection of Psalidodon (Teleostei: Characidae). Zool J Linn Soc 190:1217-1234.

Toscani MA, Pigozzi MI, Bressa MJ, Papeschi AG (2008) Synapsis with and without recombination in the male meiosis of the leaffooted bug Holhymenia rubiginosa (Coreidae, Heteroptera). Genetica 132:173-178.

Turner J (2015) Meiotic silencing in mammals. Annu Rev Genet 49:395-412.
Turner JMA, Mahadevaiah SK, Fernandez-Capetillo O, Nussenzweig A, Xu X, Deng CX, Burgoyne PS (2005) Silencing of unsynapsed meiotic chromosomes in the mouse. Nat Genet 37:41-47.

Valente GT, Conte MA, Fantinatti BEA, Cabral-De-Mello DC, Carvalho RF, Vicari MR, Kocher TD and Martins C (2014) Origin and evolution of $\mathrm{B}$ chromosomes in the cichlid fish Astatotilapia latifasciata based on integrated genomic analyses. Mol Biol Evol 31:2061-2072.

Wu D, Ruban A, Fuchs J, Macas J, Novák P, Vaio M, Zhou Y and Houben A (2019) Nondisjunction and unequal spindle organization accompany the drive of Aegilops speltoides $\mathrm{B}$ chromosomes. New Phytol 223:1340-1352.

Yudkin D, Trifonov V, Kukekova A, Vorobieva N, Rubtsova N, Yang FD, Acland GMC, Ferguson-Smith MAB and Graphodatsky ASA (2007) Mapping of KIT adjacent sequences on canid autosomes and B chromosomes. Cytogenet. Genome Res 116:100-103.

Zhang J, Zhang B, Su H, Birchler JA and Han F (2014) Molecular mechanisms of homologous chromosome pairing and segregation in plants. J Genet Genomics 41:117-123.

\section{Internet Resources}

Estimation Statistics, https://www.estimationstats.com/.

\section{Supplementary material}

The following online material is available for this article:

Figure $\mathrm{S} 1$ - Detection of $P$. paranae synaptonemal complexes through immunodetection using anti-medaka SYCP3 antibody. Table S1 - Relative transcription levels for the gene $m s h 4$ in B-carrying and B-lacking individuals.

Associate Editor: Vera Maria Fonseca de Almeida e Val

License information: This is an open-access article distributed under the terms of the Creative Commons Attribution License (type CC-BY), which permits unrestricted use, distribution and reproduction in any medium, provided the original article is properly cited. 